\title{
An Implanted Antenna System for the Monitoring of Bioresorbability of a Biocompatible Scaffold Embedded into a Bone Fracture
}

\author{
Symeon Symeonidis ${ }^{1}$, Carmen Torres-Sanchez ${ }^{2}$, Chinthana Panagamuwa ${ }^{1}$ and William G. Whittow ${ }^{1}$ \\ 1. School of Electronic, Electrical and Systems Engineering, Loughborough University, Loughborough, Leicestershire, UK \\ 2. School of Mechanical and Manufacturing Engineering, Loughborough University, Loughborough, Leicestershire, UK \\ S.Symeonidis@lboro.ac.uk, C.Torres@lboro.ac.uk,c.j.panagamuwa@lboro.ac.uk,w.g.whittow@lboro.ac.uk
}

\begin{abstract}
In this paper the dielectric properties of an implanted bioresorbable scaffold that is being used for the acceleration of the healing process of a fractured bone have been investigated. An implanted antenna system is presented for the monitoring of the resorption rate of the scaffold, which gives an indication on the healing process of the bone fracture. A simulation model of a three layer body phantom was used for the evaluation of the $S_{21}$ response of the system as the introduced fracture gradually healed, turning from blood to bone marrow and bone cortical in five steps.
\end{abstract}

\section{Keywords}

Implanted antennas, bioresorbable, biocompatible, polymer, scaffold, bone phantoms, fracture monitoring

\section{INTRODUCTION}

Fracture healing in bones is a complex biological process that requires constant monitoring from doctors for the first 4 weeks. Healing depends, amongst others, on the number of discrete fractures, the type of bone and the patient's age and gender. Fracture healing is not a standard process and it is based on predetermined time points often varying from 4 to 40 weeks passing through two different phases [1]: (i) The soft callus phase, where the stem cells in the fracture change into chondrocytes, forming cartilages to bridge the gap into the fracture, and (ii) the hard callus phase where endochondral ossification occurs and the cartilages are being replaced by bone [2]-[4]. Some researchers propose a slightly different perspective regarding bone growth, grouping the healing process into (i) an anabolic phase, where the cartilage is formed, and (ii) a catabolic phase where the cartilage is replaced by bone [5] Each of these phases present complex biological and chemical processes. Work in the area of tissue engineering has yielded polymeric biomaterials that can act as temporary substitutes for bone, skin, arteries, etc [6][7]. These 3-dimensonal scaffolds play a crucial role as substrates for the cells to attach, proliferate and form a matrix which can derive to healed regenerated tissue. Any monitoring that could help decrease complications during the early stages of healing is generally desired so clinicians can provide support via intervention. For the assistance in the monitoring of the soft and hard calli phases, an implanted antenna system on the 3-dimentsional scaffold has been proposed.
Implanted antennas inside the human body often pose many obstacles for designers. Such obstacles occur due to the lossy nature of the medium that greatly decreases the efficiency of the radiator [8]-[10]. For proper transmission, it is favorable to use lower frequencies that penetrate the tissue easily but lead to bigger antenna designs. Yet, these kinds of geometries are difficult to embed due to the limited space inside the human body. In the recent years many authors have addressed this obstacle and numerous trade - offs between frequency of operation and antenna.

\section{PERMITTIVITY AND LOSS TANGENT MEASUREMENTS OF THESCAFFOLD}

Preparation of the scaffold: $0.8 \mathrm{~g}$ of PCL $15 \% \mathrm{w} / \mathrm{w}$ solution, from Fluka, and $0.2 \mathrm{~g}$ of $10 \% \mathrm{w} / \mathrm{w}$ PLLA, from Scientific Polymer Products, were mixed in $4 \mathrm{ml}$ chloroform and vigorously vortexed with $4 \mathrm{~g}$ of $\mathrm{NaCl}$ grains. The mixture was poured in a silicon mould and placed in an oven at $40{ }^{\circ} \mathrm{C}$ for 4 days. The scaffolds were then washed with copious amounts of deionized water and left to dry in the oven at $40{ }^{\circ} \mathrm{C}$ for 4 days. The resultant product was a fine strip of white and flexible polymer (figure 1a).

In order to measure the permittivity and loss tangent of the scaffold, a microwave frequency Q meter attached to a Split Post Dielectric Resonator (SPDR) was used operating at 2.4 $\mathrm{GHz}$ (Fig.1a). The thickness of the biopolymer strips was $1.6 \mathrm{~mm}$, the relative permittivity was measured at 1.367 , the loss tangent at 0.0256 and the conductivity at $0.004 \mathrm{~S} / \mathrm{m}$.

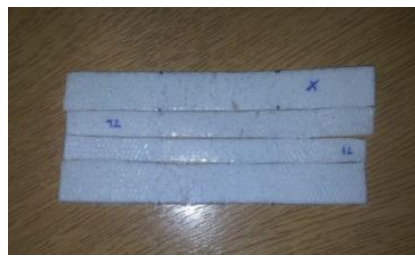

(a)

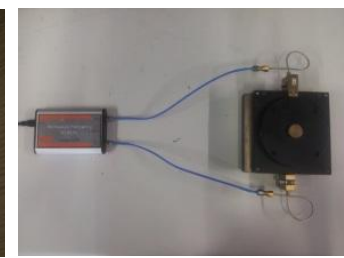

(b)
Figure 1: (a) The PCL/PLLA scaffold strips, (b) The Q meter and the SPDR

\section{THE PROPOSED ANTENNA SYSTEM}

The antenna system consisted of two monopoles with individual metal ground planes, identified as Monopole A and B. The length of each monopole was $65 \mathrm{~cm}$ and the radius $1 \mathrm{~mm}$, the dimensions of each ground plane were $4.9 \times 6 \mathrm{~cm}$ and were separated by a $0.2 \mathrm{~cm}$ gap. The distance between the monopoles 
was set at $2 \mathrm{~cm}$ (Fig. 2). A biocompatible coating encased the monopoles in order to insulate them from each layer of the body phantom. The material used was PEEK having a relative permittivity of 3.2 and $a \tan \delta$ of 0.01 at $2.4 \mathrm{GHz}$ [21].

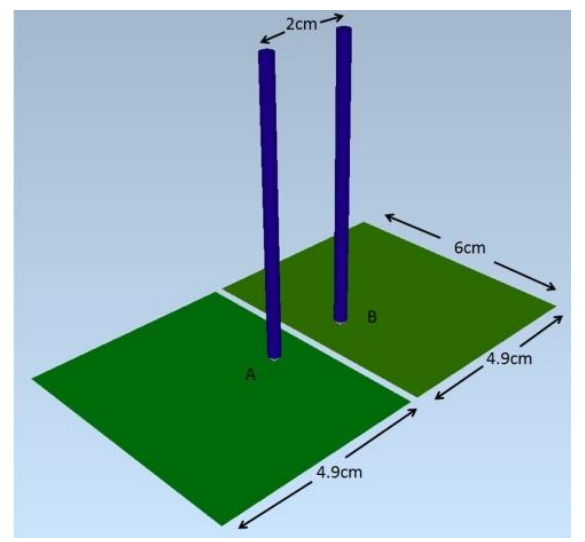

Figure 2: The antenna system

For the simulation of the fractured bone, a phantom consisting of three layers (marrow, cortical and muscle) was used (Fig.3a). Each cylinder had $15 \mathrm{~cm}$ length. The inner cylinder representing bone marrow had a radius of $1.2 \mathrm{~cm}$, the middle representing bone cortical had $1.5 \mathrm{~cm}$ radius and the outer cylinder representing muscle had $10 \mathrm{~cm}$ radius. Table 1 shows the dielectric properties of bone marrow, bone cortical and muscle at $2.4 \mathrm{GHz}$ that were appointed to the cylinders. A fracture was introduced in the middle of the phantom that consisted of two concentric cylinders of $2 \mathrm{~mm}$ thickness each. The first cylinder had the radius of bone marrow $(1.2 \mathrm{~cm})$ and the second the radius of bone cortical $(1.5 \mathrm{~cm})$. In order to simulate the condition of the fracture five different states were considered that corresponded to the healing process of the fracture from blood to bone. At the initial state, the scaffold was considered to occupy the area of the cylinder that represents bone cortical by $50 \%$, along with blood. The relative permittivity and conductivity of the scaffold were added to the relative permittivity and conductivity of blood and the resulting values were divided by 2 . The inner cylinder was assigned with the properties of blood. Both cylinders changed with a $25 \%$ step towards the properties of bone marrow and bone cortical until the bone was considered fully healed and the scaffold completely degraded (Table 2). The two monopoles of the proposed system were placed on either side of the fracture (Fig. $3 \mathrm{~b}$ ) in order to investigate the properties of the propagation from monopole A to monopole $\mathrm{B}$.

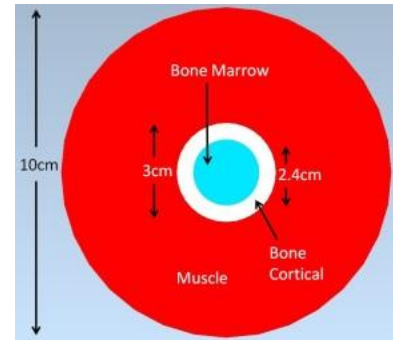

(a)

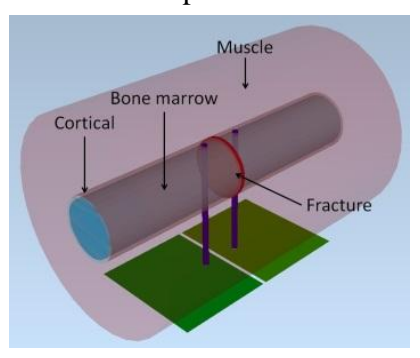

(b)
Figure 3: The three layer phantom: (a) front view (b) side view
Table 1: The dielectric properties used for the three layered bone phantom [22]

\begin{tabular}{|l|c|c|}
\hline & $\begin{array}{c}\text { Relative } \\
\text { Permittivity } \\
\varepsilon_{r}\end{array}$ & $\begin{array}{c}\text { Conductivity } \\
\sigma,(\mathrm{S} / \mathrm{m})\end{array}$ \\
\hline Muscle & 52.79 & 1.7 \\
\hline Bone Marrow & 5.30 & 0.09 \\
\hline Bone Cortical & 11.41 & 0.38 \\
\hline Blood & 58.3 & 2.5 \\
\hline
\end{tabular}

Table 2: The dielectric properties of the fracture during the healing progress [22]

\begin{tabular}{|c|c|c|c|c|}
\hline & \multicolumn{2}{|c|}{ Bone Marrow } & \multicolumn{2}{c|}{ Bone Cortical } \\
\hline $\begin{array}{c}\text { Bone } \\
\text { Damage }\end{array}$ & $\begin{array}{c}\text { Relative } \\
\text { Perm. } \\
\varepsilon_{r}\end{array}$ & $\begin{array}{c}\text { Cond. } \\
\sigma,(\mathrm{S} / \mathrm{m})\end{array}$ & $\begin{array}{c}\text { Relative } \\
\text { Perm. } \\
\varepsilon_{r}\end{array}$ & $\begin{array}{c}\text { Cond. } \\
\sigma,(\mathrm{S} / \mathrm{m})\end{array}$ \\
\hline $100 \%$ & 58.3 & 2.5 & 29.83 & 1.25 \\
\hline $75 \%$ & 50.35 & 1.98 & 25.22 & 1.03 \\
\hline $50 \%$ & 31.8 & 1.29 & 20.62 & 0.81 \\
\hline $25 \%$ & 18.55 & 0.69 & 16.01 & 0.59 \\
\hline $0 \%$ & 5.3 & 0.09 & 11.41 & 0.38 \\
\hline
\end{tabular}

It is envisaged that two metallic pins representing the boneembedded part of the monopoles will be inserted into the bone during the initial medical procedure where the scaffold is inserted. The bottom section of the dipole will then be formed by inserting two insulated needles through the skin to make direct contact with the embedded pins. The needles will then be connected externally to the feeding co-axial cable and ground plane. In this way, the microwave signal can be applied to the two monopoles as and when a measurement is needed.

\section{SIMULATION RESULTS}

In order to simulate the proposed structure, the EMPIRE XPU electromagnetic solver was used. Table 2 describes the change of the dielectric properties of the fracture in five steps. Figure 5 shows that as the fracture changes properties from blood and scaffold to bone, the $S_{21}$ magnitude at $1.26 \mathrm{GHz}$ from step 1 to step 2 improves by $0.85 \mathrm{~dB}$, from step 2 to step 3 by $1.1 \mathrm{~dB}$ and more than $1 \mathrm{~dB}$ for each of the next steps, see Table 3 . This trend shows that it is possible to monitor the changes inside the broken bone when the biodegradable scaffold is applied to the fracture. 


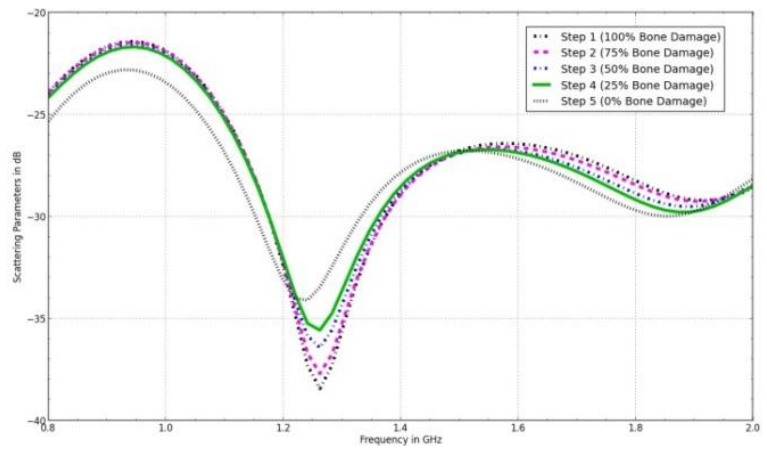

Figure 4: The $S_{21}$ of the monopoles with the dielectric properties of the fracture changing from blood to bone in five steps

Table 3: The $S_{21}$ response at $1.25 \mathrm{GHz}$ for each step of the bone fracture

\begin{tabular}{|c|c|}
\hline & $S_{21}$ \\
\hline $100 \%$ Bone Damage) & -38.3 \\
\hline $75 \%$ Bone Damage) & -37.5 \\
\hline $50 \%$ Bone Damage) & -36.4 \\
\hline $25 \%$ Bone Damage) & -35.3 \\
\hline $0 \%$ Bone Damage) & -33.5 \\
\hline
\end{tabular}

\section{CONCLUSION}

The dielectric properties of a biodegradable scaffold used for the acceleration of the healing process of fractured bones have been presented. These properties were used for the simulation of a three layered bone phantom where an implanted antenna system was used in order to measure the healing process of the fracture in terms of $\boldsymbol{S}_{\mathbf{2 1}}$ magnitude. The results showed that as the fracture where the bioresorbable scaffold was implanted changed to bone, the $\boldsymbol{S}_{\mathbf{2 1}}$ response between the monopoles improved. Future work includes further investigation of the proposed structure in an anatomical model. Since the purpose of the antenna system is to monitor bone healing, it is also important to establish the propagation characteristics through the scaffold when there is a complication with the healing process. In terms of the scaffold, its dielectric properties as it degrades will need further investigation in a laboratory setting.

\section{REFERENCES}

[1] P. Augat, M. Faschingbauer, K. Seide, K. Tobita, S. a. Callary, L. B. Solomon, and J. H. Holstein, "Biomechanical methods for the assessment of fracture repair," Injury, vol. 45, pp. S32-S38, 2014.

[2] C. Colnot, X. Zhang, and M. L. K. Tate, "Current insights on the regenerative potential of the periosteum: Molecular, cellular, and endogenous engineering approaches," J. Orthop. Res., vol. 30, no. 12, pp. 1869-1878, 2012.

[3] C. S. Bahney, D. P. Hu, A. J. Taylor, F. Ferro, H. M. Britz, B. Hallgrimsson, B. Johnstone, T. Miclau, and R. S. Marcucio, "Stem cell-derived endochondral cartilage stimulates bone healing by tissue transformation," J. Bone Miner. Res., vol. 29, no. 5, pp. 1269-1282, 2014.
[4] K. D. Hankenson, G. Zimmerman, and R. Marcucio, "Biological perspectives of delayed fracture healing," Injury, vol. 45, pp. S8-S15, 2014

[5] D. G. Little, M. Ramachandran, and a Schindeler, "The anabolic and catabolic responses in bone repair.," J. Bone Joint Surg. Br., vol. 89, no. 4, pp. 425433, 2007.

[6] A. G. Mikos, A. J. Thorsen, L. a Czerwonka, Y. Bao, R. Langer, D. N Winslow, and J. P. Vacanti, "Preparation and characterization of poly(1-lactic acid) foams," Polymer (Guildf)., vol. 35, no. 5, pp. 1068-1077, 1994.

[7] C. M. Agrawal and R. B. Ray, "Biodegradable polymeric scaffolds for musculoskeletal tissue engineering," J. Biomed. Mater. Res., vol. 55, no. 2, pp. $141-150,2001$

[8] C. J. Panagamuwa, W. G. Whittow, R. M. Edwards, and J. C. Vardaxoglou, "A Study of the Effects of Metallic Pins on SAR using a Specific Anthropomorphic Mannequin (SAM) Head Phantom," no. EuCAP, pp. 1-6, 2007.

[9] C. J. Panagamuwa, W. Whittow, R. Edwards, J. C. Vardaxoglou, and P. McEvoy, "A study of the validation of RF energy specific absorption rates for simulations of anatomically correct head FDTD simulations and truncated DASY4 standard equipment measurements," Eur. Sp. Agency, (Special Publ. ESA SP, vol. 626 SP, 2006.

[10] W. G. Whittow and R. M. Edwards, "A Study of changes to specific absorption rates in the human eye close to perfectly conducting spectacles within the radio frequency range 1.5 to $3.0 \mathrm{GHz}$," IEEE Trans. Antennas Propag., vol. 52, no. 12, pp. 3207-3212, 2004.

[11] J. Kim and Y. Rahmat-Samii, "Implanted antennas inside a human body: Simulations, designs, and characterizations," IEEE Trans. Microw. Theory Tech., vol. 52, no. 8, pp. 1934-1943, 2004

[12] P. Soontornpipit, C. M. Furse, and Y. C. Chung, "Design of implantable microstrip antenna for communication with medical implants," IEEE Trans. Microw. Theory Tech., vol. 52, no. 8, pp. 1944-1951, 2004.

[13] T. Karacolak, A. Z. Hood, and E. Topsakal, "Design of a dual-band implantable antenna and development of skin mimicking gels for continuous glucose monitoring," IEEE Trans. Microw. Theory Tech., vol. 56, no. 4, pp. 1001$1008,2008$.

[14] W. Xia, K. Saito, M. Takahashi, and K. Ito, "Performances of an implanted cavity slot antenna embedded in the human arm," IEEE Trans. Antennas Propag., vol. 57, no. 4, pp. 894-899, 2009.

[15] R. Warty, M. R. Tofighi, U. Kawoos, and A. Rosen, "Characterization of implantable antennas for intracranial pressure monitoring: Reflection by and transmission through a scalp phantom," IEEE Trans. Microw. Theory Tech., vol. 56 , no. 10 , pp. 2366-2376, 2008.

[16] P. Mohseni, K. Najafi, S. J. Eliades, and X. Wang, "Wireless multichannel biopotential recording using an integrated FM telemetry circuit," IEEE Trans. Neural Syst. Rehabil. Eng., vol. 13, no. 3, pp. 263-271, 2005.

[17] A. Sani, M. Rajab, R. Foster, and Y. Hao, "Antennas and propagation of implanted RFIDs for pervasive healthcare applications," Proc. IEEE, vol. 98, no. 9, pp. 1648-1655, 2010 .

[18] E. Y. Chow, A. Kahn, and P. P. Irazoqui, "High data-rate $6.7 \mathrm{GHz}$ wireless ASIC transmitter for neural prostheses," Annu. Int. Conf. IEEE Eng. Med. Biol. - Proc., pp. 6580-6583, 2007.

[19] Y. Ahmed, Y. Hao, and C. Parini, “A 31.5 GHz Patch Antenna Design for Medical Implants,” Int. J. Antennas Propag., vol. 2008, pp. 1-6, 2008. 
[20] F. Khan, R. S. Tare, J. M. Kanczler, R. O. C. Oreffo, and M. Bradley,

"Strategies for cell manipulation and skeletal tissue engineering using high-

throughput polymer blend formulation and microarray techniques," Biomaterials, vol. 31, no. 8, pp. 2216-2228, 2010.

[21] A. Kiourti, K. a. Psathas, and K. S. Nikita, "Implantable and ingestible medical devices with wireless telemetry functionalities: A review of current status and challenges," Bioelectromagnetics, vol. 35, no. 1, pp. 1-15, 2014.

[22] S. Gabriel, R. W. Lau, and C. Gabriel, "The dielectric properties of biological tissues: II. Measurements in the frequency range $10 \mathrm{~Hz}$ to $20 \mathrm{GHz}$.," Phys. Med. Biol., vol. 41, no. 11, pp. 2251-2269, 1996. 
